\title{
Atividade Antinociceptiva e Antimicrobiana da Casca do Caule de Psidium Cattleyanum Sabine.
}

\author{
ALVARENDA, F.Q.'; ROYO, V.A.'; MOTA, B.F.C.'; LAURENTIZ, R.S.2; MENEZES, E.V.*1; MELO JUNIOR, \\ A.F.'; OLIVEIRA, D.A. ${ }^{1}$ \\ 1 Universidade Estadual de Montes Claros, Campus Universitário Professor Darcy Ribeiro, Av Ruy Braga S/N, \\ CEP 39401-089, Vila Mauricéia, Montes Claros - MG, Brasil, 2Universidade Estadual Paulista - Departamento \\ de Física e Química da Faculdade de Engenharia de Ilha Solteira, Av Brasil, 56, CEP 15385-000, Ilha Solteira- \\ SP, Brasil. *Autor para correspondência: menezes.elytania@gmail.com
}

RESUMO: Psidium cattleyanum Sabine, conhecida como "araçá", é espécie nativa do Bioma Cerrado brasileiro comumente utilizado, segundo levantamento etnobotânico, como planta medicinal para tratar várias doenças tais como: patologias hepáticas, gástricas, lesões teciduais incluindo processos dolorosos. O objetivo deste trabalho foi realizar a triagem fitoquímica com propósito exploratório, investigar a atividade analgésica e antimicrobiana do extrato hidroalcoólico da casca do caule de Psidium cattleyanum Sabine (ECPCS) para apoiar o uso dessa espécie como planta medicinal. Para isso, foram obtidos extratos e frações com solventes orgânicos de polaridade crescente (hexano, diclorometano, acetato de etila e isobutanol) avaliando-se o perfil fitoquímico para determinar as principais classes de metabólitos secundários presentes na espécie. Investigou-se a atividade analgésica pelo teste de contorções abdominais em camundongos induzidas pelo ácido acético $(0,6 \%)$. A Concentração Inibitória Mínina (CIM) e Concentração Bactericida Mínima (CBM) foram avaliadas através da técnica de microdiluição em caldo contra micro-organismos da microbiota oral. A triagem fitoquímica identificou a presença de taninos, saponinas, flavonoides e terpenos e/ou esteroides. O ECPCS exibiu atividade analgésica periférica nas doses de 200 e $400 \mathrm{mg} / \mathrm{kg}$. O EAC (extrato acetato de casca) o EDC (extrato diclorometânico de casca) desempenharam melhor ação inibitória sobre o crescimento bacteriano de Estafilococos oralis com CIM 100 e 150 respectivamente. O ECPCS desempenhou ação inibitória sobre o crescimento bacteriano. Os resultados dos estudos experimentais comprovaram a presença de compostos secundários tais como, taninos e flavonoides, o que, provavelmente, pode ser associado à atividade analgésica e ao efeito inibitório sobre os micro-organismos testados com o ECPCS, o que justifica o uso medicinal planta.

Palavras Chave: Myrtaceae, araçá, atividade biológica, inibição álgica, atividade antibacteriana.

\begin{abstract}
Antiniciceptive and antimicrobial activity of the stem bark of Psidium cattleyanum Sabine. The Psidium cattleyanum Sabine, known as "araçá", is a native species from the Brazilian Cerrado biome, commonly used, according to ethnobotanical surveis, as a medicinal plant to treat several sicknesses such as liver and, gastric diseases and tissue lesions with painful treatments. The aim of this study was to perform an exploratory screening, investigating the analgesic and antimicrobial activity of the hydroalcoholic extract of the Psidium cattleyanum Sabine (BEPCS) stem bark, in order to support the use of this species as a medicinal plant. For that, the BEPCS and its parts were obtained from the extraction with organic solvents of increasing polarity (hexane, dichloromethane, ethyl acetate and isobutanol), evaluating its phytochemical profile in order to determine the main types of secondary metabolites present in the species. The analgesic activity, through the twisting test in mice, was investigated and induced by acetic acid (0.6\%). The Minimum Inhibitory Concentration (MIC) and Minimum Bactericidal Concentration (MBC) were evaluated using the microdilution technique in liquid against microorganisms of the oral microbiota. The phytochemical screening identified the presence of tannins, saponins, flavonoids and terpenes and/or steroids. The BEPCS exhibited peripheral analgesic activity at the doses of 200 and $400 \mathrm{mg} / \mathrm{kg}$. The AEB (acetate extract
\end{abstract}

Recebido para publicação em 06/11/2014

Aceito para publicação em 22/07/2015

10.1590/1983-084X/14_146

Rev. Bras. PI. Med., Campinas, v.17, n.4, supl. III, p.1125-1133, 2015. 
bark) and the DEB (dicloromethane extract bark) had better inhibitory effect on bacterial growth of Staphylococcus oralis with MIC 100 and 150 respectively. The BEPCS demonstrated an inhibitory effect on bacterial growth. The results of experimental studies have indicated the presence of secondary compounds as tannins and flavonoids, which probably can be associated with the analgesic activity and inhibitory effect on the microorganisms tested with BEPCS, fact that justifies the its application.

Keywords: Myrtaceae, araçá, biological activity, inhibition algic, antibacterial activity.

\section{INTRODUÇÃO}

O Bioma Cerrado é dos principais núcleos de biodiversidade genética do planeta e Brasil possui ampla área territorial (do norte ao sul do país). Outros tipos de riqueza em biodiversidade podem ser encontrados na Floresta Amazônica, na Caatinga e Mata Atlântica, principais Biomas ocorrentes no território brasileiro. Infelizmente, a área do Cerrado tem se tornado vulnerável devido ao avanço da fronteira agrícola, sendo devastada em função do desenvolvimento da agroindústria (Silva et al, 2008). O Psidium cattleyanum Sabine, conhecido vulgarmente como araçá, araçá-docampo, araçá-vermelho é membro da família Myrtaceae, ocorre naturalmente no Brasil, sendo nativa no Bioma do Cerrado. É uma espécie herbácea, que pode atingir até 2,5 metros de altura, possui uma copa foliar abundante, tronco com casca lisa, fina e descamativa, conhecida como araçazeiro. Os frutos da espécie são pequenos, globosos, apresentam numerosas sementes e ocorrem de forma abundante. Assemelham-se à goiaba (Psidium guajava), embora apresentem sabor mais ácido, odor mais acentuado e menores no seu tamanho. São riquíssimos em vitamina $C$, além disso, podem apresentar o exocarpo amarelado ou rosado e o endocarpo, apresentase com uma polpa comestível suculenta de cor creme (Brandão et al, 2002; Bezerra et al, 2006; Franzon et al, 2004; Pino et al, 2001). Estudos recentes comprovaram que essa espécie é empregada como planta medicinal por apresentar atividades biológicas distintas, enfatiza-se o seu potencial analgésico periférico, antitumoral e atividade antimicrobiana contra diversos microorganismos (Alvarenga et al, 2013; Medina et al, 2011); Jun et al, 2011; Im et al, 2012; Souza et al, 2004; Desoti et al, 2011). Além disso foi descrita a ação anti-cariogênica em ratos onde o extrato de Psidium cattleyanum confirmou atividade contra a composição microbiana do biofilme da mucosa oral (Menezes et al, 2010). Apesar de sua importância, pesquisas de cunho fitoquímico abordando especificamente as mirtáceas brasileiras ainda são escassos (Desoti et al, 2011). No Brasil, o uso medicinal descrito pela sabedoria popular envolve a utilização da espécie em estudo para tratar diarréia, auxiliar no processo de cicatrização e regeneração de lesões teciduais, adstringente, antidiarréico e analgésico (Ritter et al, 2002; Vendruscolo et al, 2005; Vendruscolo \& Mentz, 2006). Um levantamento etnobotânico sobre o uso da espécie do gênero Psidium em diferentes regiões do país revelou que as folhas e cascas do caule são usadas sob a forma direta, através da mastigação ou chá, por efusão, também foi descrito o uso tópico da planta em solução aquosa ou alcoólica e uso oral para alívio de dores, como dor de dente, dor de barriga, dor de garganta e dor abdominal (Alvarenga et al, 2013; Vendrusculo et al. 2005; Vendrusculo \& Mentz 2006).

\section{METODOLOGIA \\ Material Vegetal}

Foram coletadas cascas $(25 \mathrm{~g}$ de cada indivíduo) de forma aleatória das espécies de $P$. cattleyanum Sabine no município de Glaucilândia (Minas Gerais - Brasil) (coordenadas 1651'00"S

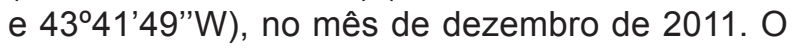
material foi seco espontaneamente, à sombra, por um período de quatro dias, depois, pulverizado em moinho tipo Wiley, armazenado em sacos de papel à $-10^{\circ} \mathrm{C}$ (Alvarenga, et al, 2013). Uma amostra do material vegetal, em exsicata, foi identificada pelo pesquisador da Universidade Estadual de Montes Claros - Minas Gerais (UNIMONTES-MG), Dr. Rubens Manoel dos Santos, e, a mesma, foi depositada no herbário dessa mesma instituição sendo protocolado com o número 3533.

\section{Extratos Hidroalcoólicos e Frações}

O extrato hidroalcoólico foi preparado pelo método de maceração exaustiva, utilizando-se 200 $\mathrm{g}$ do material vegetal pulverizado em $1000 \mathrm{~mL}$ de etanol/água $(7: 3 \mathrm{v} / \mathrm{v})$. 0 extrato foi armazenado protegido da luz por sete dias e, após esse período, foi homogeneizado, filtrado, evaporado e refrigerado $\mathrm{a}-10^{\circ} \mathrm{C}$. $\mathrm{O}$ mesmo procedimento foi realizado com o resíduo obtido da filtração por três semanas consecutivas. Obtendo-se para o extrato bruto $17,56 \mathrm{~g}(8,78 \%)$.

As frações foram obtidas a partir de $10 \mathrm{~g}$

Rev. Bras. PI. Med., Campinas, v.17, n.4, supl. III, p.1125-1133, 2015. 
do extrato bruto seco das cascas do caule de $P$. cattleyanum sob agitação vigorosa com solventes orgânicos de polaridade crescente. Cada grama de extrato bruto seco foi tratado com duas porções de $30 \mathrm{~mL}$ de hexano, diclorometano, acetato de etila e isobutanol respectivamente. O solvente foi evaporado sob pressão reduzida em evaporador rotativo e armazenadas à $-10^{\circ} \mathrm{C}$. Os extratos particionados, após secagem, foram pesados e os rendimentos calculados obtendo-se para a fração

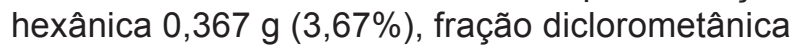
$0,378 \mathrm{~g}(7,38 \%)$, fração acetato de etila $0,330 \mathrm{~g}$ $(3,30 \%)$ e fração isobutanólica $0,723 \mathrm{~g}(7,23 \%)$.

\section{Análise Fitoquímica Preliminar}

Foi realizada uma triagem fitoquímica preliminar, com material vegetal pulverizado, para na análise qualitativa da presença de alcaloides, saponinas, taninos, fenois, antraquinonas, flavonoides e esteróis, utilizando os métodos previamente descritos por Tona et al, (1998); Mouco et al, (2003) e Barbosa et al, (2001).

\section{(CLAE)}

\section{Cromatografia Líquida de Alta Eficiência}

As análises exploratórias foram realizadas em cromatógrafo líquido de alta eficiência (Waters), equipado com injetor automático e detector de diodo, as frações foram solubilizadas em metanol a $1 \mathrm{mg} / \mathrm{mL}$. As condições cromatográficas utilizadas foram: coluna cromatográfica $\mathrm{C} 18$ de alto desempenho (Phenomenex), $250 \times 4,6 \mathrm{~mm}, 10$ $\mu \mathrm{m}$, modo de eluição isocrático, volume de injeção de $10 \mu \mathrm{L}$, vazão da fase móvel de $1,0 \mathrm{~mL} / \mathrm{min}$ e a fase móvel foi composta por uma mistura de água em metanol na proporção de $80: 20$, acidificada a $1 \%$ com ácido acético.

\section{Ensaio Animal}

Para os ensaios de atividade antinociceptiva foram utilizados 48 camundongos Swiss albinos, fêmeas, com peso médio entre 20 $\mathrm{g}$ e $30 \mathrm{~g}$. Os animais passaram por um período de sete dias de adaptação em gaiolas, recebendo água e ração comercial ad libitum até doze horas antes da realização do experimento. Cada grupo foi constituído de seis animais. Todos os procedimentos foram aprovados sob o número de protocolo 001/ 2012 pela Comissão de Ética no Uso de Animais (CEUA) da Faculdade de Engenharia da UNESP - Ilha Solteira, Brasil. Os instrumentos de coleta de dados elaborados visaram atender aos aspectos éticos de acordo com as diretrizes internacionais para o cuidado e uso de animais de laboratório, publicado pelo Instituto Nacional de Saúde dos Estados Unidos.

\section{Atividade Antinociceptiva}

A avaliação da atividade antinociceptiva do extrato hidroalcoólico da casca de $P$. cattleyanum Sabine foi realizada a partir da técnica de contorções abdominais induzidas por ácido acético descrita por Koster et al, (1959). Após serem tratados por via oral $(0,1 \mathrm{~mL}) \mathrm{com}$ os extratos hidroalcoólicos nas concentrações de 100, 200 e 400 mg/kg de peso, usando como controle negativo, solução de tween 80 a $5 \%$ em salina (veículo) e para o controle positivo, solução de indometacina $5 \mathrm{mg} / \mathrm{kg}$ (em todos os tratamentos foi utilizado o mesmo veículo), induziuse a nocicepção com injeção intraperitonial de ácido acético a $0,6 \%$. Foram tomadas como respostas as contorções abdominais seguidas de alongamento de todo o corpo e os resultados obtidos equivalentes à média \pm erro padrão da média (EPM) do número de contorções no intervalo de 20 minutos após o tratamento. Os resultados foram submetidos à análise estatística seguindo os modelos One-Way ANOVA e Teste de variância de Dunnett.

\section{Atividade Antimicrobiana}

Micro-organismos utilizados

Foram utilizadas as seguintes cepas padrão oriundas da American Type Culture Collection (ATCC): Streptococcus mutans (ATCC 25175), Streptococcus salivarius (ATCC 7073), Streptococcus oralis (ATCC 10557), Lactobacillus rhamnosus (ATCC 9595). As cepas utilizadas para a realização dos ensaios microbiológicos foram cedidas pela Fundação Osvaldo Cruz (FIOCRUZ).

\section{Concentração Inibitória Mínima (CIM)}

Foi realizada a técnica de microdiluição em placas de poliestireno estéreis, descrita pelo NCCLS (2008), para determinação da CIM dos extratos brutos e frações da casca de $P$. cattleyanum Sabine. A CIM foi definida como a menor concentração do extrato capaz de inibir o crescimento bacteriano (NCCLS, 2008; Lee et al, 2007). Os extratos hidroalcoólicos e as frações foram esterilizados por filtração através de membrana de acetato celulose $(0,22 \mu \mathrm{m})$ e avaliados nas concentrações 500, 400, 300, 200, 150, 100, 50, 40, 30, 20 e $10 \mu \mathrm{g} / \mathrm{mL}$. Como controle positivo, utilizou-se solução clorexidina nas concentrações de 0,12\%, 0,20\% e 1,0\% e, como controle negativo, meio de cultura (Caldo Muller Hinton) com solução salina $0,85 \%$ de $\mathrm{NaCl}$ e Tween a $5 \%$. Foram realizados os testes de esterilidade do meio, do solvente e o teste de viabilidade da cultura. $O$ inoculo foi padronizado comparando-o com o tubo 0,5 da escala de McFarland $(0,1 \mathrm{~mL}$ de cloreto de bário a $1,0 \%$ + 9,9 mL de ácido sulfúrico a 1,0\%) por meio da leitura das absorbâncias e $625 \mathrm{~nm}$. As microplacas

Rev. Bras. PI. Med., Campinas, v.17, n.4, supl. III, p.1125-1133, 2015. 
utilizadas no teste foram tratadas previamente pelo processo de esterilização química com solução de hipoclorito de sódio a 5\% por 24 horas, em seguida, foram submetidas à luz ultravioleta por 30 minutos. Os testes foram realizados, utilizando microplacas diferentes para cada cepa testada, para não ocorrer contaminação cruzada. As microplacas contendo extrato, controle e inoculo foram incubadas por 24 horas a $37^{\circ} \mathrm{C}$, após esse período foram adicionados $10 \mu \mathrm{L}$ de solução aquosa de resazurina a $0,02 \%$ e novamente incubadas por 60 minutos. A interpretação dos resultados foi descrita pela variação de coloração nos orifíciios, sendo que a manutenção da cor azul foi interpretada como ausência de crescimento microbiano e a cor vermelha ou rósea como presença crescimento bacteriano no meio.

Concentração Bactericida Mínima (CBM) Para a determinação da CBM, foi utilizada a metodologia descrita por Murari et al, (2008) sendo realizada após a leitura visual das microplacas com resazurina e determinação das CIM. Todos os orifícios onde não foi observado o crescimento bacteriano foram repicados em placas contendo ágar Mueller Hinton e incubados por 24 horas a $37 \circ \mathrm{C}$. A CBM foi determinada pela ausência de crescimento bacteriano após incubação. A inibição do crescimento bacteriano na CIM e observação do desenvolvimento bacteriano em placa foram consideradas como ação bacteriostática do extrato testado. A inviabilização do crescimento do microorganismo com a menor concentração de um determinado composto com ação bactericida foi definido como Concentração Bactericida Mínima (CBM).

\section{Análise dos dados}

Os resultados foram analisados estatisticamente por análise de variância (ANOVA) seguida pelo teste de Tukey \& Dunnett. Foram considerados significativos valores de $p<0,05$, quando comparados com o controle negativo (veículo). Todos os valores foram expressos como média \pm erro padrão da média (EPM).

\section{RESULTADOS \\ Análise Fitoquímica \\ O estudo fitoquímico foi capaz de identificar} taninos, saponinas, flavonoides e terpenos e/ ou esteróides todavia, não detectou alcaloides, antraquinonas e glicosídeos cardioativos.

\section{CLAE}

Neste experimento foram observados os seguintes resultados para as frações do ECPCS: $\mathrm{Na}$ fração hexânica foram eluídos sete compostos, sendo dois majoritários com Tempo de Retenção (TR) de 2,707min. e 3,515min. ocupando 47,47 $\%$ e $22,49 \%$ de área respectivamente (Figura 1). Na fração diclocometânica, observou-se a presença de sete compostos, com dois majoritários, apresentando área de 65,09 \% (TR = 2,681 min.) e $13,14 \%$ (TR = 3,090 min.) (Figura 2). Na fração acetato de etila, foram eluídas sete substâncias, havendo predomínio de três delas 49,47\% (TR = 2,698 min., 15,64 \%; (TR = 3,069 min.) e 14,70 \% ( $T R=3,716$ min.) (Figura 3). Na fração mais polar, a isobutanólica, foram observados oito compostos eluídos com presença de três majoritários $40,10 \%$ ( $T R=2,685$ min.), 23,27 \% (TR = 3,816 min.) e 12,47 $\%(\mathrm{TR}=3,513 \mathrm{~min}$.) (Figura 4).

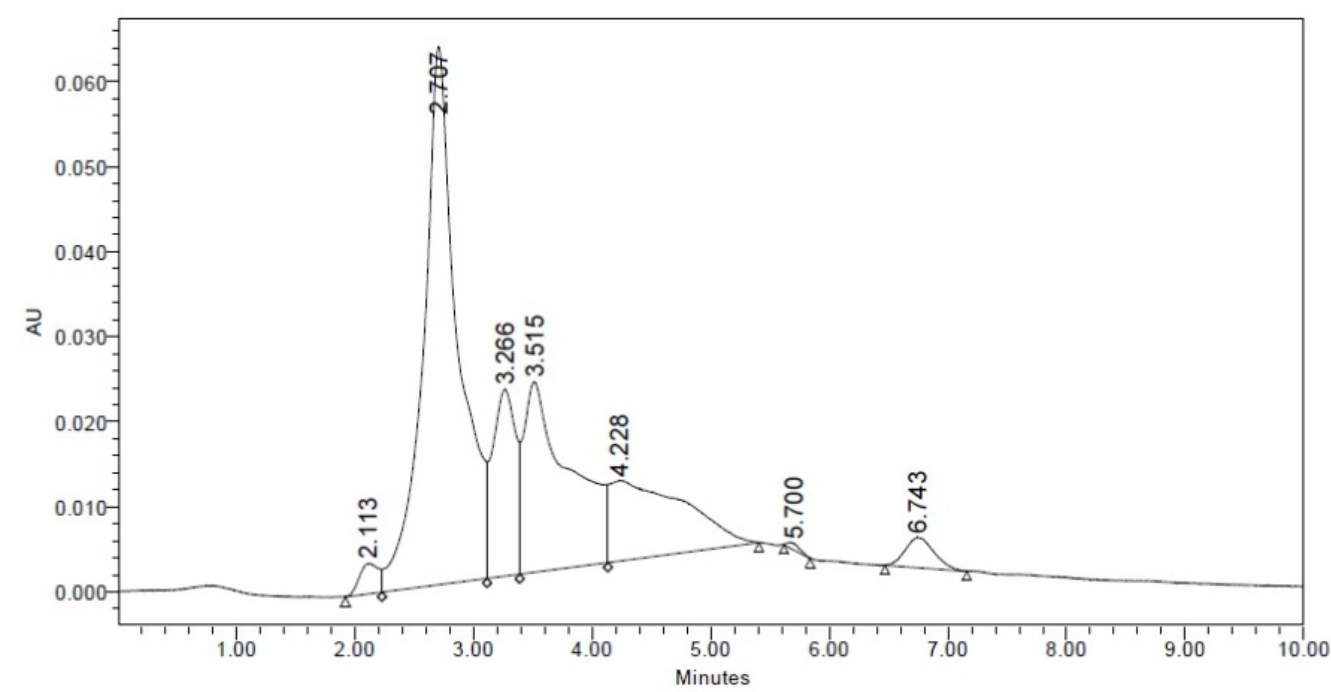

FIGURA 1. Fração hexânica com sete compostos eluídos, sendo dois majoritários com Tempo de Retenção (TR) de 2,707min. e 3,515min. ocupando $47,47 \%$ e $22,49 \%$ de área.

Rev. Bras. PI. Med., Campinas, v.17, n.4, supl. III, p.1125-1133, 2015. 


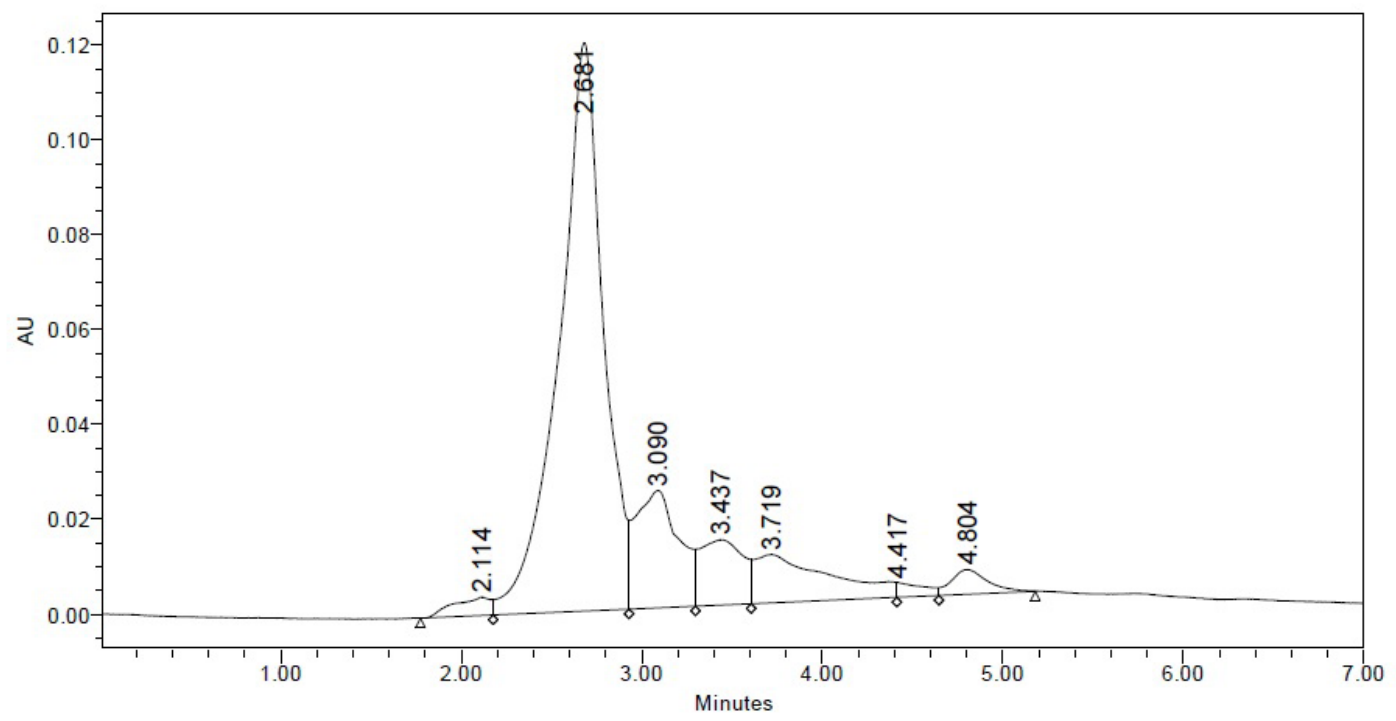

FIGURA 2. Fração diclocometânica, observando-se a presença de sete compostos, com dois majoritários, apresentando área de $65,09 \%$ (TR = 2,681 min.) e 13,14 \% (TR = 3,090 min.).

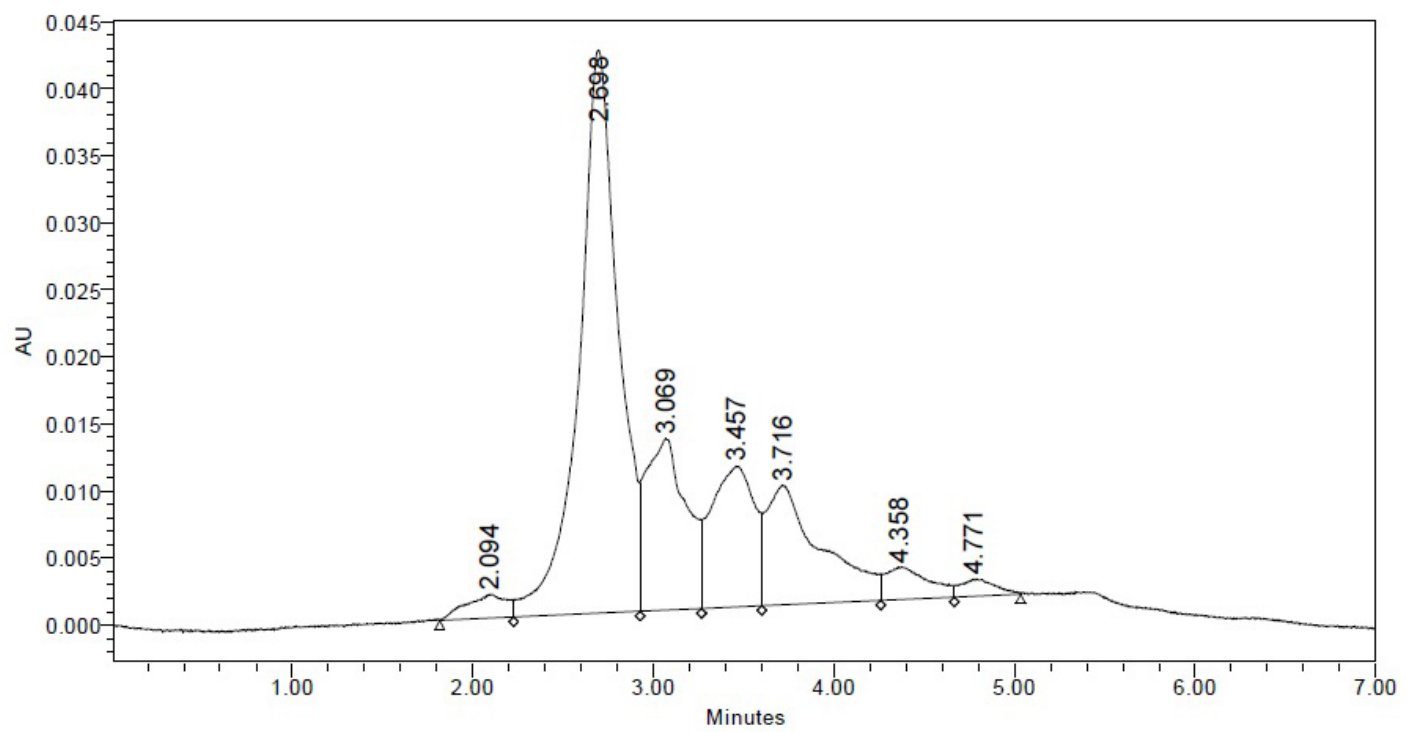

FIGURA 3. Fração acetato de etila, onde pode-se observar, sete substâncias eluídas, havendo predomínio de três delas 49,47\% (TR = 2,698 min., 15,64 \%; (TR = 3,069 min.) e 14,70 \% (TR=3,716 min.)

\section{Analgesia periférica}

Os resultados do efeito do ECPCS sobre o número de contorções abdominais induzidas pelo ácido acético $(0,6 \%)$ estão expressos na Figura 5.

\section{Atividade Antimicrobiana}

Os extratos brutos e partições da casca do caule de $P$. cattleyanum Sabine foram testados contra quatro micro-organismos e os resultados estão expressos na tabela 1.

\section{DISCUSSÃO}

Nos resultados das análises fitoquímicas das cascas do caule de $P$. cattleyanum Sabine não foi detectado a presença de alcaloides, glicosídeos cardiotônicos e antraquinonas; mas foi observada a presença de saponinas através da formação de espuma estável em grande quantidade. As saponinas são substâncias derivadas do metabolismo secundário das plantas, relacionadas, principalmente com o sistema de defesa. São encontradas nos tecidos vegetais mais susceptíveis ao ataque de predatório de insetos, fungos e bactérias exercendo ação "fitoprotetora", estudos indicam que essa atividade seria provocada pela interação das saponinas com os esteróis das membranas celulares (Francis et al, 2002). É válido dizer que outras atividades sobre as membranas celulares tais como, hemolítica, antiviral, ictiotóxica 


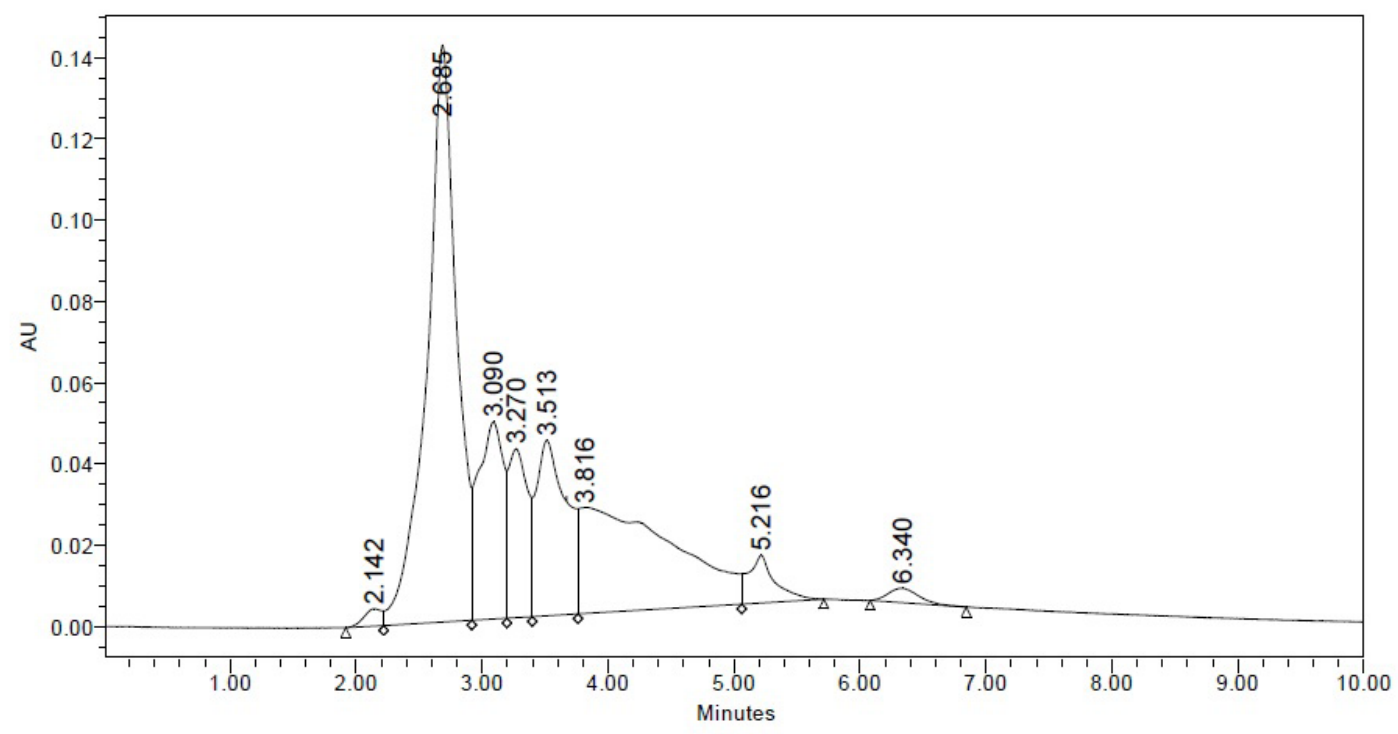

FIGURA 4. Fração isobutanólica, onde foram observados oito compostos eluídos com presença de três majoritários 40,10\% (TR = 2,685 min.), 23,27 \% (TR = 3,816 min.) e 12,47 \% (TR = 3,513 min.)

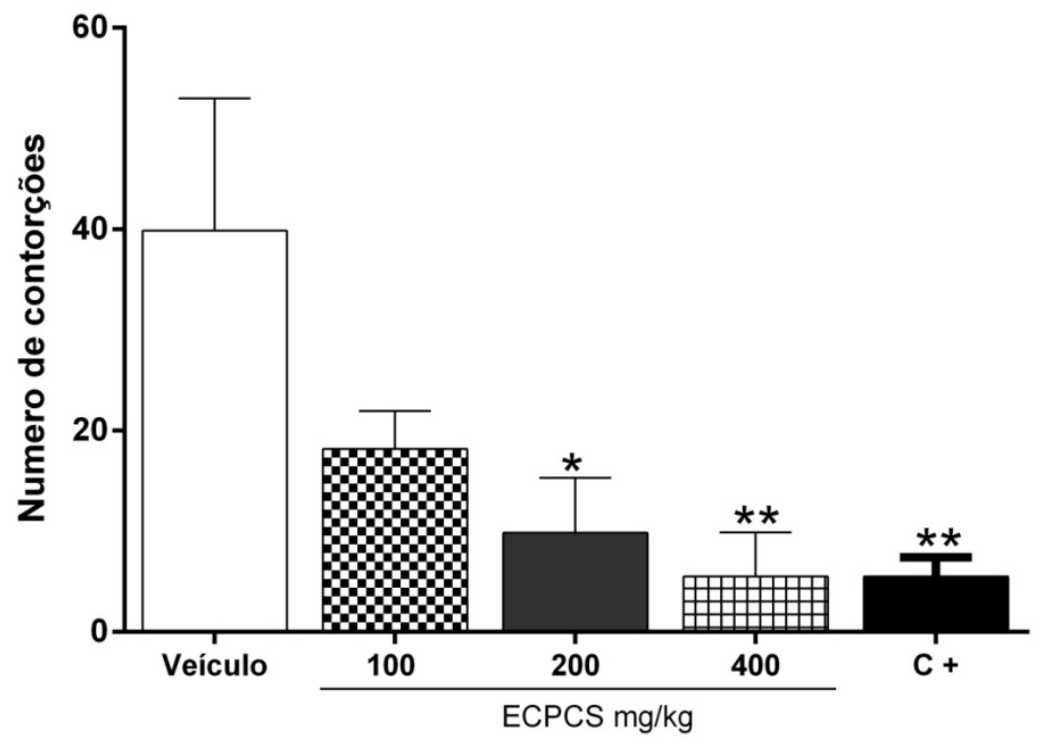

FIGURA 5. Efeito do ECPCS no ensaio de contorções abdominais induzidas pelo ácido acético (0,6\%). Veículo (controle negativo), ECPCS (100, 200 e $400 \mathrm{mg} / \mathrm{kg}$ ), Indometacina (C+, $5 \mathrm{mg} / \mathrm{kg}$ ), foram administrados 30 minutos antes da injeção intraperitoneal de ácido acético. As colunas e barras verticais representam as médias \pm 0 erro padrão em grupos experimentais de seis animais comparados com controle. ${ }^{*} p<0,05 ;{ }^{* *} p<0,001$.

TABELA 1. CIM e CBM $(\mu \mathrm{g} / \mathrm{mL})$ do extrato bruto e frações da casca do caule de Psidium cattleyanum Sabine. EBHC - Extrato bruto hidroalcoólico de casca/ EHC - Extrato hexânico de casca/ EDC - Extrato Diclorometânico de casca/ EAC - Extrato Acetato de casca/ EIC - Extrato isobutanólico de casca.

\begin{tabular}{lllllllll}
\hline Extrato & \multicolumn{2}{l}{ S. salivarius } & \multicolumn{2}{c}{ S. oralis } & \multicolumn{2}{c}{ S. mutans } & \multicolumn{2}{c}{ L.rhamnosus } \\
\hline & CIM & CBM & CIM & CBM & CIM & CBM & CIM & CBM \\
EBHC & 500 & 500 & 200 & 300 & 200 & 200 & ND & ND \\
EHC & ND & ND & ND & ND & 300 & 300 & ND & ND \\
EDC & ND & ND & 150 & 150 & ND & ND & ND & ND \\
EAC & H00 & 500 & 100 & 200 & 400 & ND & ND & ND \\
EIC & ND & ND & 500 & 500 & 300 & 200 & ND & ND \\
\hline
\end{tabular}

Resultados dispostos na tabela demonstram apenas as concentrações onde ocorreram inibição. ND: Nenhum dado 
e anti-inflamatória tem sido relacionadas devido a alterações na permeabilidade celular podendo levar à destruição das mesmas (Schenkel et al, 2001). Os taninos também foram evidenciados em proporções significativas pelo teste fitoquímico e, diversos estudos sobre atividade dos taninos revelaram uma importante ação antibacteriana, ação sobre protozoários e reparação de tecidos (cicatrizante). Foi também descrita a atuação regulatória dos taninos sobre algumas enzimas intracelulares. A atividade antimicrobiana exercida por essa classe de compostos ocorre por mecanismos distintos: atividade antioxidante e seqüestradora de radicais livres, complexação com íons metálicos e capacidade de se complexar com moléculas orgânicas, como, por exemplo, proteínas e carboidratos da classe dos polissacarídeos (Haslam, 1996). Outras atividades biológicas dos taninos atribuídas à fisiologia humana são: a estimulação de células fagocitárias e a ação tumoral e atividades anti-infectivas (Loguércio, 2005).

A presença de flavonoides, saponinas, triterpenos e/ou esteroides, revelada no ensaio fitoquímico, pode estar diretamente relacionada à analgesia periférica induzida pelo ECPCS (Cody et al, 1985; Mutalik et al, 2003; Owoyele et al, 2008).

A atividade analgésica do ECPCS foi avaliada pela técnica de contorções abdominais induzidas pelo ácido acético que inclui estimulo nociceptivo periférico e central para fornecer resposta de analgesia frente ao dano tecidual induzido pelo ácido, todavia, essa técnica tem maior empregabilidade sobre a ação álgica periférica (Zhou et al, 2008; Steranka et al, 1987; Wang et al, 2013; Habib \& Waheed, 2013). A ação nociceptiva do ácido acético desencadeia a liberação de substâncias químicas endógenas (Gyires \& Torna, 1984; Berkenkopf, et al, 1988). Deraedt et al (1980) observaram a presença desses compostos em níveis elevados durante os trinta primeiros minutos após a injeção intraperitoneal de ácido acético. Dentre os compostos observados, foram identificados as prostaglandinas, bradicininas e outros mediadores químicos. Foram analisados os números de contorções de cada grupo e o ECPCS apresentou um percentual de inibição de dor de $54,39 \% ; 75,31 \%$ e $86,19 \%$ em resposta ao tratamento com o extrato nas doses de 100, 200 e 400 mg/kg respectivamente. Verificou-se que em cada tempo os animais tratados com ECPCS apresentaram um elevado percentual de inibição de dor quando comparadas como veículo sendo estatisticamente significativos nas doses de 200 $\mathrm{mg} / \mathrm{kg}(p<0,05)$ e $400 \mathrm{mg} / \mathrm{kg}(p<0,001)$. Estes resultados foram análogos ao grupo controle, que apresentou uma porcentagem de $86,19 \%$ de inibição álgica, sugerindo desta forma uma elevada atividade analgésica periférica do extrato desta planta.

No estudo da ação antimicrobiana os melhores resultados foram observados para CIM do EAC contra S. oralis $(100 \mu \mathrm{g} / \mathrm{mL})$ e CBM do EDC $(150 \mu \mathrm{g} / \mathrm{mL})$. Para $S$. salivarius foi observado CIM do EAC $(400 \mu \mathrm{g} / \mathrm{mL})$ e $S$. mutans as CIM e CBM os melhores resultados são do EBHC $(200 \mu \mathrm{g} / \mathrm{mL}$ para ambos). Porém, os resultados não demostram eficácia dos extratos testados contra a linhagem de Lactobacillus rhamnosus.

A atividade antimicrobiana observada por essa espécie vegetal e por outras espécies pertencentes à família Myrtaceae, relaciona-se com o alto teor de substâncias como óleos essenciais, taninos e compostos fenólicos (Loguércio et al, 2005). Estudos realizados por Brighenti et al (2008) analisando o efeito do extrato aquoso obtido por meio da decocção em água destilada, sobre a viabilidade, expressão protéica e produção de ácidos de cepas de $S$. mutans, foi capaz de demonstrar que a presença de taninos e flavonoides presentes na espécie de $P$. cattleyanum (araçávermelho) atua como inibidores da expressão enzimática, exercendo ação antimicrobiana. Neste mesmo estudo os resultados revelaram que o extrato vegetal foi capaz de diminuir a atividade enzimática celular do S. mutans, o que inviabiliza o crescimento bacteriano impedindo a formação de ácido láctico, exercendo ação anti-cariogênica sobre os biofilmes da mucosa oral. As concentrações dos extratos de $P$. cattleyanum Sabine com ação bactericida e bacteriostática variaram entre 150 e $500 \mu \mathrm{g} / \mathrm{mL}$. Em um estudo desenvolvido por Rodrigues (2008), avaliando a sensibilidade microbiana de duas cepas ATCC, foi possível determinar a ação do extrato metanólico de folhas secas e frescas, de Psidium guineense Sw coletada no município de Glaucilândia, mesmo local de coleta do $P$. cattleyanum Sabine verificando-se que as frações de taninos extraídas apresentaram atividade antimicrobiana contra cepas de Staphylococcus aureus (ATCC 25923) e Pseudomonas aeruginosa (ATCC 27853). Desta forma, pode-se inferir que as espécies de Psidium, pertencentes à família Myrtaceae possuem atividade antimicrobiana.

A análise do perfil cromatográfico dos extratos particionados de $P$. cattleyanum Sabine revelou a ocorrência de espectros UV com picos com padrão similar de absorção em torno de 240 - 280 $\mathrm{nm}$ e $280-352 \mathrm{~nm}$, o que sugere a presença de picos compatíveis com os de flavonoides e taninos respectivamente (Row, 2006; Ugaz, 1994) e que podem ser associados às atividades analgésica e antioxidante do extrato bruto das folhas dessa espécie descritos por Alvarenga et al (2013). Pelo menos dois compostos, com Tempo de Retenção semelhantes entre 2,681 min. a 2,707 min. e 3,716

Rev. Bras. PI. Med., Campinas, v.17, n.4, supl. III, p.1125-1133, 2015. 
min. a 3,816 min. foram detectados pelo método cromatográfico em todas as frações analisadas com picos de absorção não sobrepostos compatíveis com padrões relatados na literatura para identificação de flavonoides e taninos (Jurd, 1962; Fromming et al, 1981; Harbone et al, 1975; Ramos-Tejada et al, 2002).

\section{CONCLUSÃO}

Frente aos resultados obtidos, podemos afirmar que a espécie $P$. cattleyanum Sabine (Araçá), destaca-se pelas propriedades dos extratos da casca do caule possuindo importantes atividades biológicas tais como atividade antinociceptiva e ação antimicrobiana. Pode-se inferir que o presente estudo é propício para gerar perspectivas positivas para maiores estudos com o propósito elucidativo dos metabólitos secundários responsáveis pelas propriedades biológicas do araçá que poderão ser utilizadas no desenvolvimento de produtos medicinais beneficiando a sociedade e valorizando a biodiversidade do Cerrado brasileiro.

\section{AGRADECIMENTOS}

Os autores agradecem ao Banco do Nordeste do Brasil (BNB), Fundação de Amparo à Pesquisa do Estado de Minas Gerais (FAPEMIG), ao Programa de Pós graduação em Biotecnologia (PPGB) e Pró-Reitorias de Pesquisa e PósGraduação da Universidade Estadual Paulista pelo incentivo à pesquisa e apoio financeiro e bolsas de estudo.

\section{REFERÊNCIAS}

ALVARENGA, F.Q., et al., In vivo analgesic activity, toxicity and phytochemical screening of the hydroalcoholic extract from the leaves of Psidium cattleyanum Sabine. Journal of Ethnopharmacology, v.150, n.1, p.280284, 2013.

BARBOSA, W. L.R. Manual para Análise Fitoquímica e Cromatográfica de Extratos Vegetais. Belém, Universidade Federal do Pará. n. 4. 2001. Disponivel em: www.propesp.ufpa.br/revistaic/textos_didaticos. htm. Acesso em: 15 mai. 2014.

BERKENKOPF, J.W., WEICHMAN, B.M. Production of prostacyclin in mice following intraperitoneal injection of acetic acid, phenylbenzoquinone and zymosan: its role in the writhing response. Prostaglandins v.36, p.693-709, 1988.

BEZERRA, J.E.F.; LEDERMAN, I.E.; SILVA JÚNIOR, J.F.; PROENÇA, C.E.B. Aracá. In: VIEIRA, R. F.; COSTA,T. S.; SILVA, D. B.; FERREIRA, F. R.;SANO, S. M. (Ed.). Frutas nativas da região Centro-Oeste do Brasil. 1ed. Brasília, DF: Embrapa Recursos Genéticos e Biotecnologia, 2006, p. 42-62.
BRANDÃO, M., et al., Árvores nativas e exóticas do Estado de Minas Gerais. 1a Edição. Belo Horizonte: EPAMIG, 2002, 528 p.

BRIGHENTI, F.L., et al., Effect of Psidium cattleyanum leaf extract on Streptococcus mutans viability, protein expression and acid production. Caries Research v. 42, n.2,p.148-154, 2008.

CODY, V., MIDDLETON, E., HARBORNE, J.B. Plant flavonoid in biology and medicine: biochemistry, pharmacology and structure activity relationship. 1a Edição. New York: John Wiley \& Sons Inc,1985, 680p.

DERAEDT, R., et al., Release of prostaglandins $E$ and $F$ in algogenic reation and its inhibition. European Journal of Pharmacology..v. 61, p.17. 1980.

DESOTI, V.C., et al., Triagem fitoquímica e avaliação das atividades antimicrobiana e citotóxica de plantas medicinais nativas da região oeste do estado do Paraná. Arquivos Ciência e Saúde v.15, p.3-13, 2011.

FRANCIS, G.; et al., The biological action of saponins in animal systems: a review. British Journal of Nutrition, v.88, p. 587-605, 2002.

Franzon, R.C. Caracterização demirtáceas do Sul do Brasil. Dissertação (Mestrado em Agronomia), 2004. 114p - Faculdade de Agronomia Eliseu Maciel, Universidade Federal de Pelotas, Pelotas.

FROMMING, K.H.; et al., Sorption properties of crosslinked insoluble polyvinilpyrrolidone. Journal of Pharmaceutical, v. 70, 738-743, 1981.

GYIRES, K., TORNA, Z. The use of the writhing test in mice for screening different types of analgesics. Archives Internationales de Pharmacodynamieet de Therapie v.267, p.131-40, 1984.

HABIB, M., WAHEED, I. Evaluation of anti-nociceptive, anti-inflammatory and antipyretic activitiesof Artemisia scoparia hydromethanolic extract. Journal of Ethnopharmacology v.145, p.18-24, 2013.

HARBONE, J.B.; MABRY, T.; MABRY, H. The Flavonoids . 1a Edição. New York: Academic Press, 1975. 676p.

HASLAM, E. Natural polyphenols (vegetable tannins) as drugs and medicines: possible modes of action. Journal Natural Products. v.59, p.205 -15, 1996.

IM, I., et al., The butanol fraction of guava (Psidium cattleyanum Sabine) leaf extract suppresses MMP-2 and MMP-9 expression and activity through the suppression of the ERK1/2 MAPK signaling pathway. Nutrition and cancer v.64, p.255-266, 2012.

JUN, N.J., et al., Cytotoxic activity of - caryophyllene oxide isolated from jeju guava (Psidium cattleyanum Sabine) leaf. Records of Natural Products v.5, p.242-246, 2011.

JURD, I. Spectral properties of flavonoid contents. In: Geissman, T. A. (Ed) The Chemistry of Flavonoid Compounds. 1a Edição. New York: Macmillan, 1962, 107-155.

KOSTER, R., et al., Acetic acid for analgesic screening. Federation Proceedings V.18, n 1, p. 412-416, 1959.

LEE, S.B., et al., The Antimicrobial Activity of Essential Oil from Dracocephalum foetidum against Pathogenic Microorganisms. The Journal of Microbiology, $v 1$. p.53-57, 2007.

LOGUÉRIO, A.P.; et al., Atividade antibacteriana de extrato hidro-alcoólico de folhas de jambolão (Syzygium cumini L. Skells. Ciência Ruralv. 35, n. 2, 371-376, 2005.

Rev. Bras. PI. Med., Campinas, v.17, n.4, supl. III, p.1125-1133, 2015. 
MEDINA, A.L., et al., Araçá (Psidium cattleyanum Sabine) fruit extracts with antioxidant and antimicrobial activities and antiproliferative effect on human cancer cells, Food Chemistry v.128, p>916-922, 2011.

MENEZES, T.E.C., et al., Protective efficacy of Psidium cattleyanum and Myracrodruon urundeuva aqueous extracts against caries development in rats, Pharmaceutical Biology v.48, p.300-305, 2010.

MOUCO, G.B.; et al.,Controle de qualidade de ervas medicinais. Biotecnologia Ciência e Desenvolvimento. v.31, p.68-73, 2003.

MURARI, A.L., et al., Composição e atividade antibacteriana dos óleos essenciais de Senecio crassiflorus var. crassiflorus. Química Nova, v.31, n.5, p.1081-1084, 2008.

MUTALIK, S., et al., Antipyretic and analgesic effect of leaves of Solanum melongena Linn in rodents. Indian Journal Pharmacology v.35, p.312-315, 2003.

NCCLS.-Clinical and Laboratory Standards Institute Performance Standards for Antimicrobial Disck and Dilution Susceptibility Tests for Bacteria Isolated From Animals; Approved Standard - Third Edition. CLSI document M 31-A3 (ISBN 1-56238-659-X). Clinical and Laboratory Standards Institute, 940 West Valley Road, Suite 1400, Wayne, Pennsylvania 19087-1898 USA, 2008.

OWOYELE, B.V.; et al., Analgesic, anti-inflammatory and antipyretic activities from flavonoid fractions of Chromolaena odorata. Journal of Medicinal Plants Research v.2, p.219-225. 2008.

PINO, J.A., et al.,. Characterization of volatiles in strawberry guava (Psidium cattleyanum Sabine) fruit. Journal of Agriculture Food and Chemistry v.49, p.5883-5887, 2001.

RAMOS-TEJADA, M.M., et al., Investigacion of albumina/ $(+)$-catechin system proterties.Part I: a study of the system by FTIR-UV-Vis spectroscopy. Colloids and Surfaces B: Biointerfaces, v. 24, p.297-308, 2002.

RITTER, M.R., et al., Plantas usadas como medicinais no município de Ipê, RS, Brasil, Revista Brasileira de Farmacognosia v.12, p.51-62, 2002.

RODRIGUES, C.G. Atividade antibacteriana de taninos extraídos de folhas de Psidium guineense Sw. (MYRTACEAE). 2008. 71 p. Dissertação (Mestrado em Ciências Biológicas) - Departamento de Biologia Geral, Universidade Estadual de Montes Claros Unimontes,
Montes Claros.

ROW, K.H.; JIN, Y. Recovery of catechin compounds fromKorean tea by solvent extracion. Bioresource Techmology, v. 97, p.790-793, 2006.

SCHENKEL, E.P.; GOSMANN, G.; ATHAYDE, M. L. Saponinas. In: SIMÕES, C. M.; SCHENKEL, E. P.; GOSMANN, G.; Mello, J. C. P.; MENTZ, L. A.; PETROVICK, P. R. Farmacognosia: da planta ao medicamento. 3 ed. Porto Alegre: UFSC, 2001, 597$619 p$.

SILVA, F.A.M.; ASSAD, E.D.; STEINKE, E.T.; MULLER, A.G. Clima do Bioma Cerrado. In: ALBUQUERQUE, A. C. S.; SILVA, A. G. Agricultura tropical: quatro décadas de inovações tecnológicas, institucionais e políticas. 1a Edição, Brasília, DF: Embrapa Informação Tecnológica, 2008, 93-148.

SOUZA, G.C., et al., Ethnopharmacological studies of antimicrobial remedies in the south of Brazil. Journal of Ethnopharmacology v.90, p.135-143, 2004.

STERANKA, L.R., et al., Antinociceptive effects of bradykinin antagonists. European Journal of Pharmacology v.136, p.261-262. 1987.

TONA, L., et al., Antiamoebic and phytochemical screening of some Congolese medical plants. Journal of Ethnopharmacology v.61, p.57-65, 1998.

UGAZ, L. O. De. Investigación fitoquímica. Métodos en el estúdio de productos naturales. 1a Edição, Peru: Fondo editorial de la Pontificia Universidad Católica del Perú, 1994,114-135.

VENDRUSCOLO, G.S.; et al., Etnobotânica no Rio Grande do Sul: Análise comparativa entre o conhecimento original e atual sobre as plantas medicinais nativas. Pesquisas, Botânica v.56, p.28532, 2005.

VENDRUSCOLO, G.S.; MENTZ, L. A. Levantamento etnobotânico das plantas utilizadas como medicinais por moradores do bairro Ponta Grossa, Porto Alegre, Rio Grande do Sul, Brasil, Iheringia. Série Botânica v.61, p.83-103, 2006.

WANG, Y., et al., Analgesic effects of glycoproteins from Panax ginseng root in mice. Journal of Ethnopharmacology. v.148, p.946-950, 2013.

ZHOU, M., et al., Antinociceptive and antiinflammatory activities of Aquilariasinensis (Lour.) Gilg. Leaves extract. Journal of Ethnopharmacology v.117, p.345-350. 2008. 